\title{
Actions, style and practices: how leaders ensure compassionate care delivery
}

\author{
Timothy J Vogus (1) , 'Laura E McClelland ${ }^{2}$
}

${ }^{1}$ Owen Graduate School of Management, Vanderbilt University, Nashville, Tennessee, USA

${ }^{2}$ Health Administration, Virginia Commonwealth University, Richmond, Virginia, USA

\section{Correspondence to} Dr Timothy J Vogus,

Owen Graduate School of Management, Vanderbilt University, Nashville, TN 37203, USA:

timothy.j.vogus@vanderbilt.edu

Received 28 February 2020

Revised 10 April 2020

Accepted 15 April 2020

Published Online First

30 April 2020

Check for updates

(c) Author(s) (or their employer(s)) 2020. No commercial re-use. See rights and permissions. Published by BMJ.

To cite: Vogus TJ, McClelland LE. BMJ Leader 2020:4:48-52.

\section{ABSTRACT}

Demands for more patient-centred care necessitate that leadership creates the conditions for more compassionate care that is sustainable even in periods of acute crisis. We draw on a growing body of empirical research in health services, management and medicine to highlight how the combination of interpersonal acts, leadership style and organisational structures underpins leading with compassion. We further detail how this benefits care provider well-being and patient outcomes through fostering integrative thinking and prosocial motivation. We conclude with implications for practice.

\section{INTRODUCTION}

Healthcare organisations increasingly recognise the importance of providing patient-centred care care that is customised and compassionate in order to meet the whole-person needs of patients and in turn, achieve better health outcomes. ${ }^{1}$ By compassionate care, we mean care that notices, feels and responds to the suffering of others to attempt to alleviate it. $^{2}$ Clinician well-being continues to be a chronic problem in healthcare organisations and patients highly desire compassionate care, but both become more difficult and compassion more essential during periods of acute crisis. ${ }^{3}$ Pandemics like COVID-19 create conditions that heighten the already high demands placed on clinicians and make it even more difficult to deliver high-quality care, safely. Specifically, inadequate capacity (eg, intensive care unit beds), personal protective equipment and staffing (eg, unsafe patient-staff ratios, sustained patient surges, lack of personal protective equipment, rationing medical care and repeated trauma from patient deaths). These extreme circumstances undermine the physical (eg, hospitalacquired COVID-19 or other infections, exhaustion) and mental (eg, moral distress, post-traumatic stress and depression) well-being of clinicians and their patients.

Specifically, we focus on workplace suffering of both the patients and those delivering their care. Research shows that compassionate care benefits patients ${ }^{4}$ and that patients recognise its value, despite only receiving it about half the time. ${ }^{4}$ Despite inconsistently demonstrating compassion, clinicians value compassion too. In fact, nearly twothirds of doctors and nurses believe that compassion is a critical aspect of high-quality patient care ${ }^{4}$ and in the UK, it is a core value of healthcare according to the National Health Service Constitution and compassionate leadership has particularly been detailed and emphasised in an influential report from the King's Fund. ${ }^{5}$ Instead, evidence increasingly suggests that high and increasing rates of burnout and depression among doctors and nurses ${ }^{67}$ may significantly impede clinician capacity to show compassion perhaps by causing them to miss emotional clues from patients that compassion is desired or needed. ${ }^{8}$

Although the demands of their work may make expressing compassion more difficult, clinicians benefit from experiencing and even expressing compassion. When clinicians experience compassion at work, it functions as a buffer against strain, and is associated with higher levels of well-being. ${ }^{9}{ }^{10}$ Leaders must play a crucial role in creating conditions that enable workplace compassion in order to buffer clinicians and provide care that best meets the whole-person needs of all patients. We view compassion as subsuming related concepts of empathy and sympathy. Specifically, when an individual or organisation is compassionate, it notices the pain of others (ie, sympathy), feels the pain (ie, empathy), but also includes taking action to alleviate pain (and suffering). ${ }^{11}$ Leaders set the tone for a compassionate organisation. ${ }^{12}$ Specifically, top leaders and administrators broadly design and diffuse practices (eg, hiring) whereas clinical and mid-level managers typically foster compassion through implementation of these practices and their role modelling of compassionate behaviour (ie, actions and interactions). However, in all cases, clinical, frontline (ie, mid-level) and top managers' influence on patient experience of compassion is mostly mediated through the actions and interactions of frontline care professionals with their patients. For the organisation as a whole, top managers and administrators influence and shape an organisation's culture-a system of shared values that define what is important. ${ }^{13}$ They do so by personally setting expectations and norms for desired and appropriate behaviours through both role modelling compassionate behaviours ${ }^{14}$ and implementing policies, practices and structures that enable compassion. ${ }^{2}$ Clinical and frontline managers do so by setting the microcultures of teams and units. In both cases, these policies and practices indicate what the organisation supports, values and rewards. ${ }^{15}$

We primarily draw on empirical studies from health services, management and medicine on compassion to illuminate how leading with compassion encompasses three interrelated processes-leader interpersonal acts of compassion, compassionate leadership style and finally how leaders implement practices and structures to systematically enable compassion and sustain a culture of compassion. 


\section{LEADER COMPASSIONATE ACTS AND INTERACTIONS}

Leaders' interpersonal acts of compassion in everyday encounters with patients and employees positively benefit patients ${ }^{4}$ as well as fuel expressions of compassion by employees and generate positive employee outcomes. ${ }^{916} 17$ For top managers, their interpersonal acts may have influence across the organisation, for clinical and frontline managers, their influence may be more locally circumscribed, but no less influential. Specifically, prior research finds that compassionate statements to patients, and leader inclusiveness with employees, are two conversational mechanisms through which compassion is transmitted. Lastly, compassionate interpersonal acts shown to employees also benefit employees in a variety of ways. We discuss each of these below.

Compassionate statements from care providers that express realistic understanding of a patient's circumstance and a commitment to support them in their treatment have been associated with better adherence to treatment and improved functional outcomes. ${ }^{18-20}$ For example, statements like the following reduce patient anxiety:

I know this is a tough experience to go through and I want you to know that I am here with you. Some of the things that I say to you today may be difficult to understand so I want you to feel comfortable in stopping me if something I say is confusing or doesn't make sense. We are here together, and we will go through this together (21, p373).

But even simpler formulations that convey compassion-that is, notice and empathise with suffering-'I can understand how difficult low back pain must be for you ${ }^{22}$ or non-verbal connection (eg, leaning in, less interpersonal distance, direct eye contact, smiling and nodding) yield positive emotional and functional outcomes. ${ }^{23}$ More generally, communication that confirms (conveying the legitimacy of the concern or emotion) and pursues (asks a follow-up question or offers support) compassion $^{24}$ is associated with better patient outcomes. In turn, when a care provider engages compassionately, that person is viewed as more clinically competent and trustworthy by other care providers and patients. ${ }^{25}$ In fact, when clinical and frontline leaders (eg, unit directors) display compassion and otherwise emphasise the importance of a compassionate relationship with patients, they are more likely to be seen as a role model by their subordinates. $^{26}$

Leader inclusiveness or "words and deeds exhibited by leaders that invite and appreciate others' contributions" $(17, \mathrm{p} 941)$ is another interpersonal action through which leaders can model compassion to their subordinates. In other words, inclusiveness notices, empathises with and acts on information about challenges and suffering of the frontline care providers. In a study of Neonatal Intensive Care Units, ${ }^{17}$ acts of inclusiveness shown towards employees were associated with higher levels of psychological safety, meaning they help subordinates feel more willing to take an interpersonal risk. Specifically, inclusiveness activated psychological safety, diminished the inhibiting effects of status differences and was associated with greater engagement in quality improvement work. Such empathy and increased feelings of similarity (via reduced status distance) are critical for fostering compassion among employees and between employees and their patients. $^{27}$

Compassionate acts of leaders are also valuable because they enhance the motivation and information processing of those expressing (eg, leaders) and receiving (eg, subordinates) compassion. Specifically, compassion expresses a prosocial motivation (ie, "the desire to expend effort to benefit other people", 28, p49) that connects an individual to suffering ${ }^{29}$ and heightens sensitivity to the pain and needs of other. ${ }^{30}$ That is, compassion and emotional connection to others' suffering can create a prosocial identity-images of the self as helpful, caring and benevolent - that individuals are motivated to verify and act on ${ }^{31}$ by alleviating others' (eg, patients' and/or colleagues') suffering. Cognitively, higher levels of prosocial motivation increase the diligence and meticulousness applied to tasks. ${ }^{28}$ Prosocial motivation also elicits more integrative thinking. That is, prosocially motivated individuals consider others' perspectives more comprehensively. ${ }^{32}$ The enhanced perspective taking increases cognitive flexibility and creativity both of which expand the individual's access to ideas and potential solutions to effectively help others. ${ }^{33}$ Leader inclusiveness and interpersonal compassion are useful tools for clinical, frontline and top leaders to foster compassion and its benefits.

\section{COMPASSIONATE LEADERSHIP STYLE}

Leader compassionate acts, inclusiveness and role modelling of compassion are influential, but become more widespread when they are part of a pattern of practice or coherent leadership style. ${ }^{35}$ Leadership style is a means of fostering compassion for a leader at any organisational level (ie, frontline, top) clinical or nonclinical. One style of leadership that is inherently compassionate and other oriented is servant leadership. ${ }^{36}$ Servant leadership seeks to develop and engage followers on multiple dimensionsemotional, ethical, relational and spiritual. ${ }^{37}$ Therefore, servant leadership emerges in one-on-one interactions that recognises an individual follower's uniqueness and elevates their goals, interests and needs. ${ }^{37}$ This engagement is pursued as an end in and of itself, not as a means to other instrumental outcomes (eg, higher performance). ${ }^{38}$ As such, servant leadership is highly consistent with the description of compassionate leadership in healthcarelistening to, empathising with and supporting employees. ${ }^{39}$

Although not the explicit focus of servant leadership, there is substantial evidence that when leaders prioritise follower growth and well-being, followers are more engaged and effective in their work in ways that benefit themselves and others. ${ }^{37}$ Specifically, prior research consistently finds that servant leadership is positively associated with individual employee discretionary effort (ie, citizenship behaviour) directed towards the community, ${ }^{40}$ coworkers ${ }^{41}$ and customers. ${ }^{42}$ Servant leadership is also positively related with positive behaviours that facilitate effectively working among employees including proactively collaborating and helping. ${ }^{43-45}$ The positive, other-oriented employee behaviours associated with servant leadership are consequential for customers in terms of service quality and performance, ${ }^{42}$ customer satisfaction, ${ }^{46}$ customer value cocreation ${ }^{47}$ and servant leadership is further related to a positive service climate overall. ${ }^{48}$ In healthcare contexts, servant leadership enables and empowers patients such that they feel an enhanced ability to cope with, understand and manage their illness.

At the same time, servant leadership is positively associated with better work experiences for employees including engagement, ${ }^{49}$ job satisfaction, ${ }^{50}$ meaningfulness ${ }^{51}$ psychological wellbeing ${ }^{52}$ and thriving. ${ }^{53}$ Servant leadership is negatively linked with emotional exhaustion, ${ }^{54}$ job cynicism ${ }^{55}$ and turnover intentions, ${ }^{56}$ perhaps because they feel empowered, psychologically safe and supported. ${ }^{57}$ Overall, as a compassionate leadership style, servant leadership elicits positive attitudes among followers regarding their work as well as coworker and customer-oriented behaviours that result in higher quality service and outcomes, including in healthcare contexts. ${ }^{44}$ 


\section{LEADER STRUCTURES AND A CULTURE OF COMPASSION}

Leaders also enable workplace compassion by creating and supporting organisational structures that encourage, reinforce and support the expression of compassion. Dutton et al ${ }^{2}$ refer to these structures as the social architecture of an organisation that enables compassion organising-collective noticing, collective feeling and coordinated responses to suffering. For leaders to consistently foster compassion-both interpersonally and organisationally-leaders must create, enact and champion practices that systematically enable compassion. An organisation's top leaders have greater ability to adopt and spread such practices, but clinical and frontline leaders can elicit compassion by the ways in which they customise and implement these practices in their clinical areas or units.

In healthcare organisations, recent research finds evidence of the use of compassion practices-organisational practices that reward acts of compassion, and organisational practices that provide compassionate support to employees who are suffering. ${ }^{16}$ In subsequent work, McClelland and Vogus ${ }^{58}$ found evidence that organisations also use hiring practices, specifically behavior-based interview questions regarding compassion, to select employees who are more likely to show compassion. These compassion practices are associated with higher patient experience ratings and patients reporting higher levels of caring and concern by members of the organisation. ${ }^{10} 16$

In addition to rewarding and recognising compassion, compassion practices aid care providers by creating holding environments' that allow employees to individually or collectively process their grief and regroup. ${ }^{59}$ As such, McClelland et $a l^{10}$ find that compassion practices are associated with higher levels of caregiver psychological vitality and lower levels of emotional exhaustion. Healthcare organisations are actively experimenting with new means of deploying existing emotional support personnel (eg, pastoral care staff) to compassionately help employees cope with the demands, stress and trauma of their work. For example, the Cleveland Clinic developed Code Lavenders that activate a kind of rapid response team to attend to healthcare professionals experiencing emotional distress. ${ }^{60}$ Many healthcare organisations, like the University of Virginia Health System, have instituted 'the Pause', a contemplative practice wherein a clinician calls for a moment of silence after a patient dies, in order to help the clinical team process and honour the loss of life. ${ }^{61}$ In so doing, clinicians report feeling more connected, replenished and better able to interact with the next patient or patient family member. ${ }^{61}$ Schwartz Rounds have been introduced at hundreds of healthcare organisations in order to help clinicians discuss the difficult (eg, emotional) nonclinical aspects of a patient's case as well as to build community, foster learning and increase mutual support. ${ }^{62}$

Grant $e{ } a l^{31}$ examine how employee support programmes that provide financial grants to meet emergent needs of employees express compassion and instil prosocial motivation throughout an organisation. In addition, employee support programmes also provide a structural vehicle for employees to acts on their feelings of compassion. That is, employees contribute to the employee support programme as an expression of their compassion towards their peers who are in need. ${ }^{31}$

In addition to practices that process trauma or attend to hardship, other research finds the importance of everyday practices that cultivate connection and joy also enhance compassion among employees. ${ }^{63}$ Specifically, Lilius et al find a set of positive practices that include bounded play (eg, decorating the work environment), celebrating (each other's personal and professional milestones), collective decision-making and help offering (monitoring and acting on perceived need for help) build a compassion capability that fosters high-quality connections among coworkers in a hospital department. These connections motivate them to compassionately help their colleagues when difficult circumstances arise. ${ }^{63}$

Taken separately, each compassion practice has the capacity to foster interpersonal compassion. However, more recent evidence suggests that it is a 'bundle' of compassion practices enacted jointly that fosters and sustains organisational compassion. ${ }^{58}$ Bundles of practices are especially influential because they create consistent, distinct and mutually reinforcing signals regarding what the organisation expects, supports and values. ${ }^{64}$ That is, such combinations of practices shape a 'strong' culture that offers clear guidance for employees. ${ }^{64} \mathrm{~A}$ strong culture of compassion makes clear that acting compassionately towards colleagues and patients is a foundational part of what being at work means and what makes one a good employee. 9

When combined, the range of practices detailed above work to shape a culture of compassion by-(1) infusing organisations with people likely to show compassion, increasing the organisation's collective capability, (2) sustaining the system of compassion by further normalising expectations that compassion is a valued and required behaviour at work (towards colleagues and patients), (3) replenishing the organisation's collective capacity to respond to suffering by directly attending to workplace suffering and (4) fostering high-quality connections among employees that increase attunement to suffering, the likelihood of showing empathic concern and willingness to help. ${ }^{58} 63$ At the same time, a culture of compassion permeates the social architecture of an organisation-its social networks, values and practices and routines-to enable collective coordinated responses to suffering. ${ }^{2}$ Employees experience these cultures as caring, connected and warm. ${ }^{7}$ The compassion practices and culture of compassion are reinforced and even strengthened by each behavioural enactment by local leaders and the workforce. $^{258}$ Not surprisingly, the benefits that accrue to these organisations and their members are significant-better patient and employee outcomes (eg, higher job satisfaction, lower absenteeism, improved teamwork and even fewer common physical ailments). ${ }^{65}$

Taken together, we see how top leaders critically shapethrough individual actions and style as well as bundles of practices and structures-the extent to which an organisation has a culture of compassion. Leader compassionate acts are important symbols, reminding employees of how they should act, legitimating and giving attention to noticing and responding to suffering are available to all leaders. These acts also become shared compassion stories that spread in the organisation, as a kind of artefact, reaffirming the organisation's commitment to compassion as an important organisational value. ${ }^{263}$ Leaders also play a crucial role in creating and enacting the structural conditions for compassion. Top leaders mobilise resources, and create and activate the social architecture of an organisation-practices, routines, policies and the social network that makes compassion organising possible-with frontline leaders playing a critical role in how it is deployed. ${ }^{2}$ Compassion capabilities derived from bundles of practices enable a compassionate culture and a virtuous cycle that deepens collective compassion capability.

\section{CONCLUSION}

Increasing demands for highly customised and tailored patientcentred care, delivered in a cost-effective manner, creates a 
vexing challenge for healthcare organisations and the people who work in them even in periods of normalcy. Regional disasters (eg, earthquakes, mass shootings) and ongoing crises like the COVID-19 pandemic reveal the shockingly precarious nature of the healthcare delivery system-a system whose functioning for the communities and patients they serve relies on the sustained well-being of the workforce required to deliver care. Our review of empirical research from health services, management and medicine reveals that increasing the expression of compassion and organisational capability for compassion results in better experiences and outcomes for patients and more meaningful, rewarding and sustainable work for care providers. In other words, compassion is mutually beneficial for employees, patients and organisations. We identify how leaders at all levels play a crucial role in realising these benefits. Specifically, clinical, frontline and top leaders' interpersonal actions, their overarching styles and the practices and policies they implement combine to instil a culture of compassion that influences and increases employees' behavioural and verbal expressions of compassion to the benefit of all. However, despite mounting evidence, interventions to foster compassion remain scattered, underused, and, at times, even counterproductive. We offer two overarching recommendations for all leaders to put into practice to cultivate compassionate care and a culture of compassion in the clinical areas, units or organisations they lead.

\section{Leverage leader influence to instil compassion}

Employees look to leaders to make sense of 'the way things work around here' and what it takes to be an exemplary employee. ${ }^{1535}$ The research reviewed finds that a more intentionally compassionate approach, even in brief interactions, makes a substantial difference for patients ${ }^{21}$ and sets the tone for how to interact with patients and with other care providers and employees. ${ }^{25} 26$ When leaders model compassion, they foster high-quality relationships with their employees, deepening their referent power, and in turn, strengthening their influence on employees to express compassion and guide how they do so. Leadership influence might also be leveraged during key moments like the aforementioned care encounters, but also when giving even informal performance feedback. For example, Zohar et al find in a randomised trial that providing feedback about the extent to which employees feel a frontline supervisor values safety shifts the extent to which they prioritise and talk about safety. ${ }^{66}$ By extension, clinical, frontline and top leaders could similarly coach their subordinates regarding the extent to which they exhibit and prioritise compassion. Modelling compassion in these key moments shows how to deliver care compassionately and how to lead compassionately and in doing so can cascade and spread the expression of compassion throughout an organisation from leaders to supervisors to frontline care providers to patients.

\section{Focus on compassionate systems}

In response to the epidemic of burnout among healthcare providers, ${ }^{6}$ there have been numerous recommendations for individualised coping strategies including apps and trainings related to compassion, mindfulness and resilience. Moreover, other counterproductive recommendations might be for already 'depleted' care providers to be more compassionate, generating compassion fatigue. ${ }^{59}$ Our review offers a practical guide of how to design for compassion such that it is more hardwired into the culture of the organisation and not an additional requirement for overstretched individuals. This occurs when investments are made to redeploy existing resources in service of compassion to employees $^{6061}$ or redesigned ways of working to create space and support for compassion. ${ }^{58}$ Top leaders should build on these efforts to holistically think through how they design hiring, onboarding, training, performance evaluation and compensation practices can jointly and systematically aid compassionate care delivery and an organisational culture of compassion and clinical and frontline leaders how they customise and implement them as a means to achieve healthier patients and a thriving workforce.

Twitter Timothy J Vogus @Owen4Aidan

Contributors Both authors planned, researched, wrote and revised the manuscript.

Funding The authors have not declared a specific grant for this research from any funding agency in the public, commercial or not-for-profit sectors.

Competing interests None declared.

Patient consent for publication Not required.

Provenance and peer review Not commissioned; externally peer reviewed.

\section{ORCID iD}

Timothy J Vogus http://orcid.org/0000-0002-3164-8104

\section{REFERENCES}

1 Rathert C, Wyrwich MD, Boren SA. Patient-Centered care and outcomes: a systematic review of the literature. Med Care Res Rev 2013;70:351-79.

2 Dutton JE, Worline MC, Frost PJ, et al. Explaining compassion organizing. Adm Sci Q 2006;51:59-96

3 McAlonan GM, Lee AM, Cheung V, et al. Immediate and sustained psychological impact of an emerging infectious disease outbreak on health care workers. Can J Psychiatry 2007;52:241-7.

4 Lown BA, Rosen J, Marttila J. An agenda for improving compassionate care: a survey shows about half of patients say such care is missing. Health Aff 2011;30:1772-8.

5 West M, Eckert R, Collins B, et al. Caring to change: How compassionate leadership can stimulate innovation in health care [Internet. London, UK: The King's Fund, 2017. https://www.kingsfund.org.uk/sites/default/files/field/field_publication_file/Caring_ to change Kings Fund May 2017.pdf

6 Shanafelt TD, Hasan O, Dyrbye LN, et al. Changes in burnout and satisfaction with work-life balance in physicians and the general us working population between 2011 and 2014. Mayo Clin Proc 2015;90:1600-13.

7 McHugh MD, Kutney-Lee A, Cimiotti JP, et al. Nurses' widespread job dissatisfaction, burnout, and frustration with health benefits signal problems for patient care. Health Aff 2011;30:202-10.

8 Levinson W, Gorawara-Bhat R, Lamb J. A study of patient clues and physician responses in primary care and surgical settings. JAMA 2000;284:1021-7.

9 Barsade SG, O'Neill OA. What's Love Got to Do with It? A Longitudinal Study of the Culture of Companionate Love and Employee and Client Outcomes in a Long-term Care Setting. Adm Sci Q 2014;59:551-98

10 McClelland LE, Gabriel AS, DePuccio MJ. Compassion practices, nurse well-being, and ambulatory patient experience ratings. Med Care 2018;56:4-10.

11 Sinclair S, Norris JM, McConnell SJ, et al. Compassion: a scoping review of the healthcare literature. BMC Palliat Care 2016;15:1-16.

12 Mountford J, Powis S. Compassion: a leadership imperative for health systems. BMJ Leader 2017;1:6-7.

13 O'Reilly CA, Chatman JA. Culture as social control: corporations, cults, and commitment. Res Organ Behav 1996;18:157-200.

14 Simpson AV, Farr-Wharton B, Reddy P. Cultivating organizational compassion in healthcare. J Management Organization 2019;25:1-15.

15 Zohar D, Hofmann DA. Organizational culture and climate. In: Kozlowski SWJ, ed. Oxford Handbook of industrial and organizational psychology volume 1. New York, NY: Oxford University Press, 2012: 643-66.

16 McClelland LE, Vogus TJ. Compassion practices and HCAHPS: does rewarding and supporting workplace compassion influence patient perceptions? Health Serv Res 2014:49:1670-83.

17 Nembhard IM, Edmondson AC. Making it safe: the effects of leader inclusiveness and professional status on psychological safety and improvement efforts in health care teams. J Organ Behav 2006;27:941-66.

18 Lee $Y$-Y, Lin JL. The effects of trust in physician on self-efficacy, adherence and diabetes outcomes. Soc Sci Med 2009;68:1060-8.

19 Ratanawongsa N, Karter AJ, Parker MM, et al. Communication and medication refill adherence: the diabetes study of northern California. JAMA Intern Med 2013;173:210-8

20 Kaplan JE, Keeley RD, Engel M, et al. Aspects of patient and clinician language predict adherence to antidepressant medication. J Am Board Fam Med 2013;26:409-20. 
21 Fogarty LA, Curbow BA, Wingard JR, et al. Can 40 seconds of compassion reduce patient anxiety? J Clin Oncol 1999;17:371-9.

22 Fuentes J, Armijo-Olivo S, Funabashi M, et al. Enhanced therapeutic alliance modulates pain intensity and muscle pain sensitivity in patients with chronic low back pain: an experimental controlled study. Phys Ther 2014;94:477-89.

23 Ambady N, Koo J, Rosenthal R, et al. Physical therapists' nonverbal communication predicts geriatric patients' health outcomes. Psychol Aging 2002;17:443-52.

24 Bylund CL, Makoul G. Examining empathy in medical encounters: an observational study using the empathic communication coding system. Health Commun 2005; 18:123-40.

25 Ogle J, Bushnell JA, Caputi P. Empathy is related to clinical competence in medical care. Med Educ 2013;47:824-31.

26 Wright SM, Kern DE, Kolodner K, et al. Attributes of excellent attending-physician role models. N Engl J Med 1998;339:1986-93.

27 Dutton JE, Workman KM, Hardin AE. Compassion at work. Annu Rev Organ Psychol Organ Behav 2014;1:277-304.

28 Grant AM. Does intrinsic motivation fuel the prosocial fire? motivational synergy in predicting persistence, performance, and productivity. J App/ Psycho/ 2008;93:48-58.

29 Goetz JL, Keltner D, Simon-Thomas E. Compassion: an evolutionary analysis and empirical review. Psychol Bull 2010;136:351-74.

30 Ortony A, Clore GL, Collins A. The cognitive structure of emotions. Cambridge, UK: Cambridge University Press, 1990

31 Grant AM, Dutton JE, Rosso BD. Giving commitment: employee support programs and the prosocial sensemaking process. AMJ 2008;51:898-918.

32 Weingart LR, Bennett RJ, Brett JM. The impact of consideration of issues and motivational orientation on group negotiation process and outcome. J App/ Psychol 1993;78:504-17.

33 Grant AM, Berry JW. The necessity of others is the mother of invention: intrinsic and prosocial motivations, perspective taking, and creativity. AMJ 2011;54:73-96.

34 Polman E, Emich KJ. Decisions for others are more creative than decisions for the self Pers Soc Psychol Bull 2011;37:492-501.

35 Zohar D, Luria G. Climate as a social-cognitive construction of supervisory safety practices: scripts as proxy of behavior patterns. J App/ Psychol 2004;89:322-33.

36 Greenleaf R. Servant leadership. New York, NY: Paulist Press, 1977.

37 Eva N, Robin M, Sendjaya S, et al. Servant leadership: a systematic review and call for future research. Leadersh Q 2019;30:111-32.

38 van Dierendonck D. Servant leadership: a review and synthesis. J Manage 2011;37:1228-61

39 Edwards LD, Till A, McKimm J. Meeting today's healthcare leadership challenges: is compassionate, caring and inclusive leadership the answer? BMJ Leader 2018;2:64-7.

40 Liden RC, Wayne SJ, Zhao H, et al. Servant leadership: development of a multidimensional measure and multi-level assessment. Leadersh Q 2008;19:161-77.

41 Zhao C, Liu Y, Gao Z. An identification perspective of servant leadership's effects. J Managerial Psych 2016;31:898-913.

42 Chen Z, Zhu J, Zhou M. How does a servant leader fuel the service fire? A multilevel model of servant leadership, individual self identity, group competition climate, and customer service performance. J App/ Psychol 2015;100:511-21.

43 Bande B, Fernández-Ferrín P, Varela-Neira C, et al. Exploring the relationship among servant leadership, intrinsic motivation and performance in an industrial sales setting. J Bus Indus Marketing 2016;31:219-31.

44 Garber JS, Madigan EA, Click ER, et al. Attitudes towards collaboration and servant leadership among nurses, physicians and residents. J Interprof Care 2009:23:331-40.

45 Neubert MJ, Hunter EM, Tolentino RC. A servant leader and their stakeholders: when does organizational structure enhance a leader's influence? Leadersh $Q$ 2016;27:896-910.
46 Yang Z, Zhang H, Kwan HK, et al. Crossover effects of servant leadership and job social support on employee spouses: the mediating role of employee organizationbased self-esteem. J Bus Ethics 2018;147:595-604.

47 Hsiao C, Lee Y-H, Chen W-J. The effect of servant leadership on customer value co-creation: a cross-level analysis of key mediating roles. Tourism Management 2015:49:45-57.

48 Huang J, Li W, Qiu C, et al. The impact of CEO servant leadership on firm performance in the hospitality industry. Int J Contemp Hospitality Mngt 2016;28:945-68.

49 van Dierendonck D, Stam D, Boersma P, et al. Same difference? exploring the differential mechanisms linking servant leadership and transformational leadership to follower outcomes. Leadersh Q 2014;25:544-62.

50 Mayer DM, Bardes M, Piccolo RF. Do servant-leaders help satisfy follower needs? an organizational justice perspective. E J Work Organization Psychol 2008:17:180-97.

51 Khan KE, Khan SE, Chaudhry AG. Impact of servant leadership on workplace spirituality: Moderating role of involvement culture. Pakistan J Sci Ind $R$ 2015;67:109-13.

52 Gotsis G, Grimani K. The role of servant leadership in fostering inclusive organizations. J Mgmt Develop 2016;35:985-1010.

53 Walumbwa FO, Muchiri MK, Misati E, et al. Inspired to perform: a multilevel investigation of antecedents and consequences of thriving at work. J Organ Behav 2018;39:249-61.

54 Rivkin W, Diestel S, Schmidt K-H. The positive relationship between servant leadership and employees' psychological health: a multi-method approach. German J Human Resource Management 2014;28:52-72.

55 Bobbio A, Dierendonck DV, Manganelli AM. Servant leadership in Italy and its relation to organizational variables. Leadership 2012:8:229-43.

56 Hunter EM, Neubert MJ, Perry SJ, et al. Servant leaders inspire servant followers: antecedents and outcomes for employees and the organization. Leadersh $Q$ 2013;24:316-31.

57 Schaubroeck J, Lam SSK, Peng AC. Cognition-based and affect-based trust as mediators of leader behavior influences on team performance. J Appl Psychol 2011:96:863-71.

58 McClelland LE, Vogus TJ. Infusing, sustaining, and replenishing compassion in health care organizations through compassion practices. Health Care Manage Rev 2019:1.

59 Kahn WA. Holding environments at work. J App/ Behav Sci 2001;37:260-79.

60 Gregoire C. The amazing way this hospital is fighting physician burnout. Huffington Post, 2013. Available: https://www.huffpost.com/entry/the-amazing-way-this-hosp n_4337849 [Accessed 26 Feb 2020].

61 Cunningham T, Ducar DM, Keim-Malpass J. "The Pause": A Delphi Methodology Examining an End-of-Life Practice. West J Nurs Res 2019;41:1481-98.

62 Lown BA, Manning CF. The Schwartz center rounds: evaluation of an interdisciplinary approach to enhancing patient-centered communication, teamwork, and provider support. Acad Med 2010;85:1073-81.

63 Lilius JM, Worline MC, Dutton JE, et al. Understanding compassion capability. Human Relations 2011;64:873-99.

64 Bowen DE, Ostroff C. Understanding HRM-firm performance linkages: The role of the "strength" of the HRM system. Acad Manage Review 2004;29:203-21.

65 O'Neill OA, Rothbard NP. Is love all you need? the effects of emotional culture, suppression, and work-family conflict on firefighter risk-taking and health. AMJ 2017:60:78-108

66 Zohar D, Werber YT, Marom R, et al. Modifying head nurse messages during daily conversations as leverage for safety climate improvement: a randomised field experiment. BMJ Qual Saf 2017;26:653-62. 